\title{
Philosophiques
}

\section{Gilbert Hottois, Le paradigme bioéthique. Une éthique pour la technoscience, Bruxelles, ERPI Science, 1990, 216 pages.}

\section{Georges A. Legault}

Volume 20, numéro 1, printemps 1993

URI : https://id.erudit.org/iderudit/027216ar

DOI : https://doi.org/10.7202/027216ar

Aller au sommaire du numéro

Éditeur(s)

Société de philosophie du Québec

ISSN

0316-2923 (imprimé)

1492-1391 (numérique)

Découvrir la revue

Citer ce compte rendu

Legault, G. A. (1993). Compte rendu de [Gilbert Hottois, Le paradigme

bioéthique. Une éthique pour la technoscience, Bruxelles, ERPl Science, 1990, 216

pages.] Philosophiques, 20(1), 208-209. https://doi.org/10.7202/027216ar d'utilisation que vous pouvez consulter en ligne.

https://apropos.erudit.org/fr/usagers/politique-dutilisation/ 


\section{Gilbert Hottois, Le paradigme bioéthique. Une}

éthique pour la technoscience, Bruxelles, ERPI Science, 1990, 216 pages.

\section{par Georges A. Legault}

Dans le renouveau de la réflexion éthique. telle qu'elle se manifeste par les publications récentes. la thematique de la technoscience occupe une place centrale. Il n'est pas étonnant dès lors de voir l'auteur nous proposer, par sa démarche, d'accompagner le développenent technologique d'une « pensée réflexive et critique » (p. 8). Cependant, certaines personnes pourraient être surprises par le style même de cet écrit puisque l'auteur utilise pas moins de soixante-quinze extraits d'œuvres diverses qu'il intercale à ses propos. Ce style permet ainsi deux lectures puisque le texte continu nous livre la démarche propre de l'auteur tandis que les extraits nous permettent de nous sensibiliser à la richesse et la diversité des propos apportant une réflexion sur la technique.

Suivant la première lecture, nous pouvons cerner dans un premier temps les thèmes majeurs du paradigme bioéthique (chapitres I à 5) afin de mieux saisir l'apport de la réflexion éthique (chapitres 6-g). Le paradigme bioéthique nous permet de saisir ce qui fait probleme, ce qui est à penser dans la technique. L'élément central de la réflexion sur la technologie repose sur la reconnaissance de la «technoscience » comme nouvelle approche du savoir scientifique. Il s'agit d'un renversement du rapport de la théorie (dite pure) à la pratique. La science d'aujourd'hui est essentiellement axée sur la transformation du monde. Ce concept permet d'établir une distinction importante entre l'approche classique qualifiée « d'emprise logothéorique de la contemplation et du langage naturel » et l'approche opératoire (p. i6-17). Le renversement des perspectives de la théorie, provoqué par la technoscience, produit un effet de retour sur sa propre évaluation. Dans la mesure en effet où les évaluations procèdent d'une conception anthropologique déterminée issue du modèle contemplatif. elles apparaissent dès lors comme autant de théories diverses et équivalentes. Ainsi, tant que la technoscience est perçue comme un moyen pour répondre aux fins humaines, on attend dès lors de l'anthropologie le fin mot de l'évaluation (p. 55). Nos modèles pour penser la technoscience montrent leurs limites de façon plus significative avec les technologies applicables à l'humain. La nature humaine se modifie par la technique elle-même. Cet état de fait nous amène ainsi à repenser le rapport nature-culture tel qu'il s'ètait posé dans la culture philosophique. Comment penser l'« homme naturel-culturel » (p. 7o)? Sur cette question, la technoscience semble muette pour deux raisons. D'une part, elle est axée sur le futur, futur en transformation, futurs possibles. Ouvrant ainsi le champ du possible sans référence à un passé. à une tradition ou à un mouvement dans l'histoire, rien ne peut faire apparaître du possible le soulhaitable humain (p. 95). D'autre part, n'ayant aucune référence hors d'elle-mẻme, la technoscience se présente comme la suite de l'évolution biologique et s'affirme comme autonome (p. Ioz).

C'est dans ce champ problématique que l'éthique de la technoscience s'élabore comme accompagnement de son développement. Les propos de Hottois ne visent ni à clore les débats éthiques ni à aborder des justifications 
particulières à des enjeux spécifiques. L'auteur cherche plutôt à cerner entre deux extrêmes différentes possibilités de la voie moyenne et parmi celles-ci les caractéristiques générales propres à celle qu'il nous propose. Les extrêmes sont clairs, « le choix de l'essai de tout le possible technoscientifique » et « le choix du renoncement global et de la conservation de l'homme-nature ». La voie moyenne nous propose « l'essai de certains possibles technoscientifiques en fonction de critères à déterminer » (p. 123). La voie moyenne ne peut s'élaborer que par la reconnaissance de l'importance du symbolique pour l'humain, d'une part, et par le refus d'absolutiser la fonction théorique dans une représentation dogmatique et totalitaire.

Pour élaborer des critères, Hottois nous propose une voie moyenne caractérisée par l'approche pragmatique et la référence à notre moment de l'histoire, « l'évolution en phase anthropologique » (p. 176). Ainsi on comprend mieux la définition qu'il formulait de l'homme naturel-culturel : « il convient d'entendre la définition de l'homme comme vivant (l'animal) voué au langage (au symbole et, par là, à la culture), capacité langagière qui constitue sa différence spécifique, c'est-à-dire son essence. Produisant l'homme, l'évolution génétique naturelle a produit un vivant vouéà l'évolution historiqueculturelle: un "animal symbolique" » (p. 7r). Le rapport nature-culture est le produit de l'évolution et est inseparable de la pensée sur la nature. En cette phase où l'humain est responsable de l'évolution future, il ne peut pas refuser son historicité culturelle pour préciser ses choix. C'est pourquoi l'approche sera pragmatique, approche qui admet l'impossibilité de tout prévoir mais qui ne renonce pas à affronter les questions avec le savoir dont elle dispose.

Les discussions en bioéthique reprennent effectivement ce questionnement sur l'éthique de la technoscience et il y a effectivement de nombreux discours qui s'inscrivent dans une voie moyenne. Les propos de Hottois permettent ainsi de saisir le changement profond que la réflexion sur la technoscience impose à nos schèmes de pensée. Mais pour les personnes qui s'inscrivent dans cette voie moyenne, la question de la pluralité des discours éthiques qu'on y retrouve nous invite à préciser davantage la fonction de la rationalité dans la fonction symbolique, à moins d'admettre le relativisme culturel.

Université de Sherbrooke 